\title{
Perspectivas atuais para a pesquisa EM EDUCAÇÃO PATRIMONIAL
}

\author{
Rodrigo Manoel Dias da SILVA*
}

\begin{abstract}
RESUMO: O presente artigo visa examinar as condições sociais e sociológicas que configuram transformações nas definições de urbanismo e de memória social, considerando-se que tais condições, em alguma medida, engendram perspectivas para as práticas e para a pesquisa em educação patrimonial. Trata-se de uma abordagem diagnóstica, alicerçada em revisões conceituais e em exercícios analíticos fundamentados na teoria social contemporânea, a partir da realidade brasileira. Conclui que estudos sobre a temática exigem a problematização da condição estática dos bens, das práticas ou das coletividades às quais suas políticas visam proteger, assim como demandam o reconhecimento das múltiplas e dialéticas relações entre coletividades, espacialidades e patrimonialização.
\end{abstract}

PALAVRAS-CHAVE: Educação patrimonial. Urbanismo. Memória. Sociedade.

\section{Primeiras palavras}

A literatura recente acerca da educação patrimonial tem evidenciado seu caráter multifacetado, bem como suas novas posições no contexto das políticas educativo-culturais e da economia da cultura (SCIFONI, 2017; SILVA; 2017). Tais leituras, ainda que de maneiras particulares, partem do declínio das definições tradicionais de educação patrimonial, configurado, nas últimas décadas, a partir da constatação da crise das representações monoculturais de memória e de identidade (CANCLINI, 2006) que organizavam nossa relação política com o campo cultural.

\footnotetext{
UNISINOS - Universidade do Vale do Rio dos Sinos. Escola de Humanidades e Programa de Pós-Graduação em Educação. São Leopoldo - RS - Brasil. 93022-750 - rodrigoddsilva@hotmail.com.
} 
Não obstante, as definições fixas ou estáveis de território ou de espacialidade utilizadas como matrizes de inteligibilidade para compreendermos espaços, regiões e lugares demonstram-se insuficientes face às dinâmicas globais que aceleram o tempo e encurtam as distâncias (HARVEY, 1989).

Em perspectiva analítica correlata, a teorização social contemporânea tem evidenciado transformações nos sentidos e nas práticas sociais que constituem o que designamos por urbanismo ou processos urbanos, ao mesmo tempo em ocorrem uma série de deslocamentos na definição de patrimônio cultural, sob contradições e contestações de ordem social, política e econômica. Parcela significativa dessas contradições são observadas pelo advento de posições públicas que arregimentam a diversidade, o pluralismo e o reconhecimento da multiplicidade expressiva das culturas no contexto das políticas estatais, ora via movimentos sociais e contestações matizadas por direitos culturais, ora via organismos ou agências internacionais (como a Unesco). O núcleo de muitas dessas problematizações se refere às imprecisões postas na definição de diversidade (CORTÊS, 2012), de cultura e de patrimônio cultural.

De todo modo, é possível constatar que tais deslocamentos oferecem novas paisagens sociais à educação patrimonial. Se ela foi forjada no imaginário políticopedagógico brasileiro com configurações conservatórias, talvez os múltiplos objetivos que a cercam na atualidade não mais correspondam aos fins urbanoeducativos próprios de sua constituição histórica em meados do último século, pelo menos não da mesma forma ou com os mesmos propósitos. Por que educar para o patrimônio? Para que (ou o quê) salvaguardar? Para que (ou o quê) conservar? Para que (ou o quê) proteger?

As dinâmicas transformações que redefinem nossa espacialidade urbana e nossos modos de viver nas cidades contemporâneas e as redefinições políticas presentes nas discussões atuais sobre patrimônio e memória social parecem condições suficientes para que reexaminemos a condição da educação patrimonial, bem como os modos pelos quais a assumimos como objeto de estudo ou de intervenção social. O conjunto dessas interrogações nos faz reconhecer a potência da educação patrimonial enquanto espaço de pesquisa acadêmica e de produção de conhecimento, mas também de ação escolar e de intervenções sociais catalisadoras de processos de mudança social.

No presente artigo, pretendemos examinar as condições sociais e sociológicas que visibilizam transformações nas definições de urbanismo e de memória social, considerando que tais condições, em alguma medida, engendram perspectivas para as práticas e, com efeito, para a pesquisa em educação patrimonial. Trata-se de uma abordagem diagnóstica, alicerçada em revisões conceituais e em exercícios analíticos fundamentados na teoria social contemporânea, a partir da realidade brasileira. 


\section{Urbanismo: transformações históricas e questões conceituais}

Há, na teorização social contemporânea, uma extensa literatura que objetiva recuperar os sentidos social e historicamente atribuídos à cidade e aos fenômenos urbanos, bem como ao mapeamento dos principais contornos que configuram sua vigência em nossos dias. Do ponto de vista de sua gênese e de suas configurações históricas, David Harvey (1980) definiu a cidade como uma forma de circulação geográfica do excedente econômico. Em sua formulação socialista, Harvey (1980, p.203) afirma que o urbanismo é decorrente da concentração de excedentes em algum tipo de cidade, a partir da "articulação de um espaço econômico suficientemente extenso para facilitar a concentração geográfica do excedente social". Tal concentração modula padrões de circulação geográfica, de tal forma que poderíamos supor que o que diferencia as manifestações contemporâneas do urbanismo de suas formas prévias historicamente é que as primeiras estão envoltas em uma economia (global) de maior complexidade.

Há, então, uma espécie de correspondência entre a edificação da cidade e as formas de habitá-la. Ao comentar a obra de Henry Lefebvre, Harvey (1980, p.265) menciona que "a cidade como forma edificada e o urbanismo como modo de vida têm que ser considerados separadamente entre si porque eles se separam na realidade". Tal leitura materialista do fenômeno justificar-se-ia pelo fato de que o industrialismo e o urbanismo encerram sentidos e fins sociais diversos, uma vez que "a sociedade industrial homogeneiza e a sociedade urbana diferencia" (HARVEY, 1980, p.266).

Manuel Castells (2000), por sua vez, no clássico A questão urbana, acrescenta que a simples ligação entre a forma espacial e o conteúdo cultural não pode constituir o único elemento que define a urbanização, uma vez que urbano não significa uma forma de ocupação do espaço por uma população. Ao analisar os modos pelos quais as relações entre espaço e sociedade foram sendo produzidas ao longo do tempo, particularmente recuperando estudos arqueológicos na Mesopotâmia (3.500 a.C.), Egito (3.000 a.C.) e China e Índia (3.000 a 2.500 a.C.), o sociólogo observa que os primeiros aglomerados sedentários e com maior densidade demográfica emergem como expressão e desdobramento de capacidades técnicas e de níveis específicos de organização social. No longo horizonte histórico citado, as cidades surgiram enquanto forma residencial produzida pelos membros de uma determinada sociedade, "cuja presença direta nos locais de produção agrícola não era necessária" (CASTELLS, 2000, p.42). Nesse sentido, as cidades passaram a existir em decorrência das bases do excedente agrícola, o que evidencia que, por tal prisma, o argumento de Castells (2000) assemelha-se à elaboração de David Harvey (1980). Contudo, Castells (2000) destaca que a dimensão econômica se fez condição de possibilidade para o desenvolvimento do poder religioso, administrativo 


\section{Rodrigo Manoel Dias da Silva}

e político. Tal argumento oportuniza a compreensão de que urbano e rural estão no âmago de um mesmo processo de produção das formas sociais, mesmo que estas se diferenciem.

Do ponto de vista de seus desdobramentos enquanto formas históricas, faz-se necessário reconhecermos que as relações entre urbano e rural constituem tipos socioculturais e organizacionais variados. Será, entretanto, no advento do capitalismo industrial na Europa que as experiências urbanas sofrerão influência de conflitualidades e disputas de toda ordem.

O desenvolvimento do capitalismo industrial, ao contrário de uma visão ingênua muito difundida, não provocou o reforço da cidade e sim o seu quase desaparecimento enquanto sistema institucional e social relativamente autônomo, organizado em torno de objetivos específicos. Com efeito, a constituição da mercadoria enquanto engrenagem de base do sistema econômico, a divisão técnica e social do trabalho, a diversificação dos interesses econômicos e sociais sobre um espaço mais vasto, a homogeneização do sistema institucional, ocasionam a irrupção da conjunção de uma forma espacial, a cidade, e da esfera de domínio de uma classe específica, a burguesia (CASTELLS, 2000, p.45).

Nessa condição, Castells (2000) argumenta que os processos de urbanização e a autonomia do modelo cultural urbano manifestaram-se como paradoxalmente contraditórios. A partir do final do século XIX, mesmo que sob tensionamentos, as formas industriais organizaram inteiramente as paisagens urbanas, ou seja, concentração populacional, industrialização e a difusão de culturas urbanas fizeramse elementos fundamentais da ordem urbana moderna. Para além disso, subjaz à dicotomia urbano-rural certa imprecisão ideológica que deu sentido ao mito da modernidade e plasmou a produção social das formas espaciais.

Em perspectiva conceitual:

O termo urbanização refere-se ao mesmo tempo à constituição de formas espaciais específicas das sociedades humanas, caracterizadas pela concentração significativa das atividades e das populações em um espaço restrito, bem como à existência e à difusão de um sistema cultural específico, a cultura urbana (CASTELLS, 2000, p.46).

Se David Harvey $(1989 ; 1980)$ atribui a origem das formas urbanas à circulação geográfica dos excedentes econômicos e Manuel Castells (2000) o faz conferindo centralidade às culturas urbanas em correspondência à produção social das formas espaciais, Françoise Choay (1983) dedica-se à compreensão do urbanismo e das reformas na vida coletiva nas cidades industriais. Segundo a historiadora 
francesa, há uma marcante aproximação entre o urbanismo e as consequências sociais da Revolução Industrial na Europa. Ela observa a relevância dessa nova situação a partir da realização dos primeiros recenseamentos populacionais posteriores à dita revolução. Na Inglaterra, o fenômeno do crescimento urbano iria evidenciar-se no Censo de 1801 e, na França e na Europa em geral, a partir de 1830. Londres, por exemplo, apresentaria 864.845 habitantes conforme o Censo de 1801; 1.873.676 em 1841; e 4.232.118 em 1891.

O crescimento populacional demandou intervenções públicas na vida urbana, sendo que:

Se pode definir esquematicamente esta nova ordem por um certo número de características. Em primeiro lugar, a racionalização das vias de comunicação, com a abertura de grandes artérias e a criação de estações de trem. Depois, a especialização bastante acentuada de setores urbanos (bairros de negócios que se aproximam, nas capitais, nos entornos da Bolsa, a nova Igreja; bairros residenciais na periferia, destinada aos privilegiados (CHOAY, 1983, p.14-15). [tradução nossa].

Paradoxalmente, o crescimento do urbanismo e da urbanização fizeram com que a cidade deixasse de ser uma entidade espacial bem delimitada. Tal constatação esteve na base de estratégias de ordenação da vida nas cidades. As reformas nas cidades que se industrializavam tinham por objetivo, tanto aquelas progressistas (idealizadas por Owen, Fourier ou Proudhon) quanto as culturalistas (idealizadas por Ruskin ou Morris), uma transformação positiva na vida urbana, embora o urbanismo moderno tivesse como traço a despolitização (CHOAY, 1983).

No caso do Brasil e da América Latina, a questão das cidades e da vida urbana é uma preocupação tardia, se considerarmos a temporalidade de tais questões na Europa. Milton Santos (1982) afirma que:

Nos países subdesenvolvidos há sobretudo a questão da urbanização galopante, da massa de desempregados que se amontoam nas cidades, as diferenças gritantes na renda e nível de vida, a carência de serviços essenciais, as dificuldades de alojamento, os déficits alimentares, para citar apenas alguns aspectos (1982, p.153).

O geógrafo brasileiro acrescenta ao presente diagnóstico que, para uma reflexão sistemática acerca da edificação da vida urbana, faz-se necessário considerarmos as diferenças de renda, as diferenças de consumo e os endividamentos, subempregos e desempregos, a marginalidade e as favelizações, a insegurança, o isolamento social e do Estado, bem como problemas de saúde e de acesso a direitos. Se as leituras 
anteriores, ainda que críticas, acentuaram delineamentos conceituais e questões empíricas mais gerais sobre a definição de cidade, Milton Santos (1982) enfatiza que a compreensão das temáticas da urbanização requer a confrontação entre os múltiplos excedentes econômicos próprios da economia hodierna e a condição precarizada e politicamente instável vivida pela maioria da população em países periféricos. As cidades tornam-se estruturas duais, clivadas ou multi-fragmentadas, onde a recomposição das pautas por cidadania é urgente. As cidades, portanto, são construções históricas.

Nos Estudos Urbanos contemporâneos, há uma tendência em des-ontologizar a ideia de cidade, interpretando-a como processo socioespacial e histórico. Neil Brenner (2010), destacado pesquisador anglófono, entende que urbano não corresponde necessariamente a uma realidade, condição ou forma predeterminada, tampouco evidente em si mesma. Sua definição é constituída de um quadro teórico, mediante a "interpretação de suas propriedades, expressões ou dinâmicas fundamentais" (BRENNER; SCHMID, 2016, p.331). Destaca, em perspectiva complementar, que aquilo que convencionamos nomear pelo termo urbano não existe enquanto forma em si, tratando-se, portanto, de um processo histórico, tanto quanto a urbanização corresponde a processos de transformação socioespacial.

Assim sendo, investigar os processos socioculturais que constroem as cidades contemporâneas implica reconhecer que as dimensões espaciais da urbanização são polimórficas, variáveis e dinâmicas. Ao enfatizar que a cidade não existe em si, provoca-nos a refletir sobre os múltiplos processos que a constituem, tanto aqueles que reproduzem ou conservam determinados traços, quanto outros que engendram mudanças, novas configurações ou mesmo (significativas) transformações.

\section{Memórias e espacialidades urbanas}

A relação entre os espaços urbanos e a memória social em muito já ocupou o pensamento social e as próprias interpretações sobre a América Latina presentes na literatura, na arte ou nos estudos acadêmicos. No entanto, as conflitivas dinâmicas que engendram agenciamentos socioespaciais da memória urbana no continente, demandam que reflitamos sobre três dimensões próprias à produção das memórias nas sociedades ocidentais. Em sentido geral, as dimensões expostas na presente seção textual compõem uma abordagem analítica sobre as relações entre memória e espacialidades urbanas e, como tal, sujeita-se aos limites da parcialidade desse estudo.

Primeiramente, com Joël Candau (2016), podemos identificar o esgotamento e o colapso das grandes memórias organizadas. O argumento do antropólogo francês enfatiza que, até meados do século XX, as memórias sociais estavam assentadas 
a partir de "memórias fortemente estruturadas que contribuem, no interior de um grupo ou de uma sociedade, para orientar duravelmente as representações, crenças, opiniões e para manter a ilusão de seu compartilhamento absoluto e unânime" (CANDAU, 2016, p.182). Tanto as tramas narrativas dos mitos africanos, quanto as grandes categorias organizadoras das identidades no mundo moderno, difundiam e faziam viver grandes narrativas organizadoras da memória social. Escolas, igrejas, Estados e famílias, em suas práticas, difundiam e consolidavam uma representação coletiva do passado, estável e alicerçada sobre memórias fortes, cuja centralidade política, na Modernidade, estava posta no patrimônio nacional e, com a devida ênfase, no próprio nacionalismo. No entanto, a segunda metade do século XX evidencia um recuo e mesmo um declínio das grandes referências memoriais. Iniciase um processo de individualização das memórias, onde diversas manifestações tornam-se esquecidas, mas passa a vigorar um dever de memória.

Segundo Joël Candau (2016, p.185) "todo um arsenal de argumentos, figuras retóricas e noções diversas são utilizadas para dar conta dessa evolução, considerada mais como uma verdadeira mutação e, inclusive, como uma 'fratura" 'A conjunção entre a fratura das grandes memórias coletivas e a emergência do dever da memória desenvolveu novos fios para o debate sobre a memória social na América Latina. Os estudos de Diego Díaz (2002), comentados na sequência do texto, elucidam o quanto as paisagens urbanas hodiernas são espaços oportunos para a circulação de múltiplas expressões de memória e de esquecimento, sobretudo pela denúncia das atrocidades desenvolvidas pelos regimes autoritários em nosso continente, mas também pela afirmação de dinâmicas identitárias visando seu reconhecimento público ou oficial. De certo modo, faz-se possível afirmarmos que a memória/história oficial não consegue homogeneizar as representações dos tempos vividos e as paisagens urbanas tornam-se lugares para múltiplos agenciamentos identitários.

Uma segunda dimensão a (re)discutir se refere à ampliação das definições conceituais de memória. Para Michael Pollak (1989), a memória é objeto permanente de disputa.

A memória, essa operação coletiva dos acontecimentos e das interpretações do passado que se quer salvaguardar, se integra, como vimos, em tentativas mais ou menos conscientes de definir e de reforçar sentimentos de pertencimento e fronteiras sociais entre coletividades de tamanhos diferentes: partidos, sindicatos, igrejas, aldeias, regiões, clãs, nações, etc. A referência ao passado serve para manter a coesão dos grupos e das instituições que compõem uma sociedade, para definir seu lugar respectivo, sua complementariedade, mas também as oposições irredutíveis (POLLAK, 1989, p.9). 
Manter a coesão e assegurar a defesa das fronteiras de um grupo seriam funções primordiais da memória comum. Daí decorre o entendimento de que a memória social se visibiliza nas tensões e disputas entre grupos sociais próximos, assim como sua constituição se dá com quadros de referência bastante específicos uma vez que são decorrentes de um trabalho de enquadramento das memórias. Esse trabalho é balizado por relações de poder entre forças sociais ao selecionarem o que deve ser lembrado e o que deve ser esquecido, produzindo, muitas vezes pelas mãos do Estado, uma clivagem entre memórias oficiais (ou estatais) e memórias subterrâneas (aqueles que não são enquadrados na versão oficial da memória).

Toda memória consiste em um trabalho permanente de justificação das memórias selecionadas, sujeita ao enquadramento de suas identificações coletivas e à reinterpretação constante do passado através dos materiais da História. Duas sequências argumentativas desdobram-se da elaboração de Pollak (1989). A primeira se refere à profissionalização dos agentes da memória enquanto atores ativos no controle da memória, na seleção das narrativas privilegiadas e suas testemunhas e nas respectivas correlações entre memória social e poder do Estado. A segunda refere-se à espacialização das memórias e na construção de espaços próprios para estas, no seio da vida urbana. A história das políticas culturais é marcada pela institucionalização de espaços para a cultura, para a memória e, principalmente, para o patrimônio. Casas de cultura, museus, arquivos históricos e bibliotecas públicas tornam-se redutos da memória oficial, assim como consolida-se a função de agentes públicos atuantes na formulação, salvaguarda e transmissão do patrimônio nacional, mediante gestos pedagógicos pontuais. Embora possua uma origem europeia, esse modelo de política cultural fez-se hegemônico na América Latina, mesmo diante da descontinuidade de suas políticas no continente (RUBIM, 2007).

Por fim, o terceiro elemento a considerar na construção desse diagnóstico refere-se às possíveis correspondências entre memória social e marcações urbanas. $\mathrm{O}$ arquiteto argentino Diego Díaz (2002) reitera que, com o advento da democracia, a partir dos anos de 1990, surgiram diversos memoriais no espaço público nas cidades da Província de Buenos Aires, os quais almejavam recordar as vítimas políticas da repressão estatal, manifestar repúdio a tais fatos e denunciar lugares onde práticas de violência foram realizadas. Nos termos do autor, "todas estas formas de recordação trazem ao plano social um relato privado onde o testemunho se torna memória pública" (DÍAZ, 2002, p.34) [tradução nossa].

As marcas urbanas tornam-se elementos significativos para a compreensão das dinâmicas e dos processos políticos que instituem a memória coletiva na atualidade, pois:

As marcas urbanas cristalizam, põe os fatos em evidência e, desde então, interpelam a memória de todos. Então, outros atores, outras gerações, se envolvem 
nos processos de construção da memória coletiva disparando perguntas sobre o passado. Nesse sentido, as marcas da memória constituem um ponto importante para a formação e a transmissão de identidades (DÍAZ, 2002, p.34) [tradução nossa].

Após a última ditadura argentina, cerca de cem memoriais foram criados formando um mapa particular. Suas primeiras marcas foram agenciadas pelos afetados diretamente pela ditadura, contudo, desde 1996, ao completar 20 anos do último golpe de Estado, outras marcas e outros agenciamentos surgiram. "Placas, árvores e murais com nomes de desaparecidos, fotos com seus rostos acompanhadas por frases que reivindicavam seus lugares de pertencimento (estudantes, operários, profissionais) lhes devolviam suas identidades" (DÍAZ, 2002, p.34) [tradução nossa]. Assim, surgiram instalações artísticas, placas e jardins em homenagem aos desaparecidos, principalmente na cidade de La Plata. A espacialidade de uma cidade também expressa suas memórias sociais (ao plural), bem como suas marcações urbanas, ao ressignificarem o passado argentino recente, entraram em conflitos com outras representações de poder no contexto das cidades, caso de nomes de ruas, instituições e outros espaços públicos.

Unindo cada um destes pontos é possível detectar que as marcas de horror e as marcas da vida convivem nos espaços urbanos dando lugar a uma topografia da memória. Sem dúvida, não são somente símbolos, mas matéria que interpela a outros e os põem em relação ao passado comum. Assim como as cidades que tiveram maior quantidade de vítimas ou estiveram mais próximas a detenções clandestinas são as que mais têm trabalhado a marcação de espaços de memória. Este fato não fala de uma reação frente ao horror, mas uma política de memória contra o esquecimento: marcar as cidades é parte de um exercício coletivo, de uma prática que centraliza a lembrança (DÍAZ, 2002, p.39) [tradução nossa].

Em síntese, as três dimensões diagnósticas citadas enunciam certas configurações políticas da memória social, as quais produzem e reproduzem lugares de memória (NORA, 1993). Conforme Silvina Fabri (2011, p.171), tais memórias efetivam processos de lugarização, lugares onde uma memória específica diferencia-se da trama urbana que lhe circunda. Em tal sentido, a autora afirma que:

Falar de lugar supõe pensar em como esse espaço é vivido e apropriado em seu vínculo com a própria experiência do sujeito, tanto prática e materialmente, como mental e simbolicamente; estes níveis não podem se dissociar caso se pretenda compreender a complexidade da construção destes 'enclaves territoriais' onde se constrói uma memória (FABRI, 2013, p.95) [tradução nossa]. 
Por 'enclaves territoriais', Fabri (2013) entende a ideia de que os espaços são delimitados por uma dimensão política ou jurídico-política (em referência ao poder), uma dimensão simbólica ou cultural (dimensão subjetiva) e uma dimensão econômica (dimensão produtiva). A referida distinção é importante para entendermos as políticas de memória como práticas de marcação territorial. "Resulta evidente que não se pode falar de uma memória única e que as temporalidades diversas imprimem à construção da memória coletiva uma característica de constante reatualização", são "processos assentados em um entretecido complexo em constante tensão" (FABRI, 2013, p.103 [tradução nossa]).

\section{Educação patrimonial: discussões contemporâneas e perspectivas para pesquisa}

Verifica-se, na atualidade, um conjunto de abordagens que diagnosticam um conjunto de transformações na definição de patrimônio cultural, de educação patrimonial e, em geral, de processos de patrimonialização cultural. Desde as últimas décadas do século XX, a ideia de patrimônio cultural, enquanto categoria de pensamento oportuna à compreensão das sociedades ocidentais (GONÇALVES, 2003), tem sido rediscutida e suas significações cada vez mais ampliadas. Novas categorias de bens ou de práticas socioculturais são incorporadas ao léxico oficial que arregimenta os setores públicos e privados que tratam do setor, tornando cada vez mais obsoletas definições de patrimônio fundamentadas na pedra e na cal. Hoje, fala-se em patrimônios tangível e intangível, patrimônio ambiental, paisagístico, patrimônios vivos, patrimônios naturais, etc., Patrimônios, ao plural.

Há, nessas movimentações, uma evidente tendência à patrimonialização das diferenças (ABREU, 2015), vista pela ampliação das categorias identitárias consideradas plausíveis para a definição e seleção de patrimônios (mulheres, negros, quilombolas, indígenas, camponeses, dentre outros). Há, ainda, um recrudescimento nos propósitos de patrimonialização, considerando-se o expressivo número de inscrições de bens no rol de patrimônios da Organização das Nações Unidas para a Educação, a Ciência e a Cultura (UNESCO), do Instituto do Patrimônio Histórico e Artistico Nacional (IPHAN) ou de órgãos estaduais/setoriais de patrimônio. De algum modo, portanto, podemos identificar um alargamento nas definições de patrimônio, sob múltiplos usos, interesses e significações - econômicos, turísticos, políticos, jurídicos, educacionais ou sociais. Do ponto de vista societário, poderíamos nos indagar sobre os recorrentes esforços para evitar a morte social do patrimônio (VALECILLO, 2016)? Por que isso tem ocorrido?

Em que pese algumas mudanças na Historiografia e em posições acadêmicas mais amplas, a noção de educação patrimonial também sofre mudanças. De categoria 
vinculada originalmente às metodologias de ensino de História e à alfabetização patrimonial no Brasil, suas políticas e práticas passam a ser mobilizadas sob finalidades igualmente plurais. De posições institucionalmente delimitadas por funções de conservação patrimonial e dos interesses estatais, no contemporâneo, as escolas passam a mobilizar-se na seleção, na salvaguarda e na promoção de processos de patrimonialização vinculados às marcações socioculturais e comunitárias de suas cidades. A expressão anglófona Heritage Education trazida ao país na década de 1980 e constituída matriz cognitiva para o que conhecemos como educação patrimonial é, em nosso tempo e em nossas práticas, cada vez mais colocada em xeque.

No horizonte dessas mudanças, vislumbramos novas perspectivas para a pesquisa em educação patrimonial, as quais serão consideradas nos tópicos seguintes.

a) O exame dos verbos empregados na formulação de objetivos e de missões para as iniciativas em educação patrimonial evidencia uma representação conservatória (ou terapêutica) acerca da relação dos seres humanos com os espaços em que habitam. Proteger, salvaguardar, salvar, conservar ou reparar expressam uma perspectiva de estabilidade relativa aos patrimônios cultural ou histórico, estabelecendo uma óbvia relação de necessidade. Contudo, no contexto de suas ações pedagógicas, poucas vezes temos discutido sobre os motivos pelos quais devemos protegê-los ou sobre quem são seus oponentes. Quem ganha ou perde se determinado bem patrimonial for deteriorado? Quem ganha ou perde se aquela prática artesanal for esquecida?

Há, em tais interpelações, dois desdobramentos investigativos que, de maneira sucinta, precisamos mencionar. Primeiramente, nossos estudos precisam problematizar a condição estática dos bens, das práticas ou das coletividades às quais nossa política visa proteger. Em segundo lugar, reconhecer as múltiplas e dialéticas relações entre coletividades, espacialidades e patrimonialização. Levar em consideração tais interpretações permite-nos examinar com atenção as formas pelas quais as cidades são produzidas e os processos sociais, políticos e econômicos que condicionam espaços, dinâmicas urbanas e suas expressões culturais.

b) Há uma íntima relação entre memórias sociais, territórios urbanos e patrimônios culturais. Ao longo do tempo, a seleção dos patrimônios, predominantemente públicos, foi realizada por agências capazes de preservar o poder do Estado. Nos termos de Pollak (1989), vigoraram processos de enquadramento das memórias, nos quais as memórias subterrâneas eram 
desconstituídas ou eliminadas pela memória oficial. As leituras estadocêntricas produzidas excluíam da representação estatal coletividades empobrecidas e politicamente desconsideradas, tais como negros, indígenas, mulheres e diversos outros. Patrimônio cultural no Brasil era a herança remanescente da tradição lusitana no país, tanto quanto educar para o patrimônio significava reproduzir tal panteão. No limiar do século XXI, as referidas populações historicamente ausentes vêm negociando o reconhecimento oficial de suas histórias e identidades e sendo, não de modo alheio a disputas, inseridas nas lógicas político-institucionais (SILVA, 2015). Esse reenquadramento parte da percepção conceitual e política de que as memórias sociais e os padrões de representação estão em permanente litígio e dependem da capacidade dos atores para sustentarem sua legitimidade em um universo democrático de reivindicações.

c) No que tange especificamente à educação patrimonial, precisamos examinar a experiência dos atores engajados em tais programas e iniciativas, ou seja, precisamos identificar e analisar o que tem sido chamado por educação patrimonial. O termo experiências urbano-educativas, ancorado na Sociologia da Experiência de François Dubet (1994), parece-nos um adequado conceito operatório para um exame dessa forma educativa na atualidade. Tais experiências podem ser interpretadas pelos processos socioculturais através dos quais os atores sociais produzem suas identificações e pertencimentos (modos de sentir) e constroem as realidades urbanas onde habitam (atividades cognitivas). Nesse horizonte intelectual, ao produzirem políticas e práticas de educação patrimonial mobilizam (ou agenciam) experiências urbano-educativas, pois, ao problematizarem quais são seus patrimônios e dimensioná-los pedagogicamente, indagam sobre si próprios (experiência) e sobre as configurações socioespaciais dos lugares onde vivem. Semelhantes escolhas conceituais, enquanto estratégia de leitura das políticas e das práticas de educação patrimonial, tendem a evidenciar as diversas contradições e dilemas que constituem a condição urbana contemporânea e as políticas que conformam a vida coletiva (BRENNER; SCHMID, 2016).

As experiências urbano-educativas podem evidenciar as diversas expressões educacionais em espaços não-escolares, uma vez que muitas dessas iniciativas agenciam a educação como estratégia político-interventiva para o enfrentamento das desigualdades e vulnerabilidades sociais principalmente em periferias urbanas. Diversos estudos e pesquisas sobre políticas culturais no Brasil e na América do Sul evidenciam a existência de 
políticas que arregimentam cultura, patrimônio e educação patrimonial em projetos sociais, as quais inscrevem-se em regimes diversificados de intervenção social em bairros e regiões periféricas das cidades. Analisar as experiências dos atores sociais nesses contextos faz sentido em um cenário de patrimonialização das diferenças (ABREU, 2015), uma vez que a prerrogativa estatal de seleção e definição patrimonial tem sido relativizada e diversas comunidades e atores sociais passam a agir por seus patrimônios, indistintamente ao fato de existir chancela dos órgãos patrimoniais. Caso, por exemplo, de processos identitários e de pertencimento que têm sido mobilizados, nas escolas, para evitar a morte social dos patrimônios ou associando tais patrimônios a ações turísticas ou outras atividades com finalidades econômicas.

Em suma, não é possível investigarmos a educação patrimonial sem que consideremos os atores que a produzem e as condições sociopolíticas e históricas dessa produção.

\title{
CURRENT PERSPECTIVES FOR RESEARCH IN PATRIMONIAL EDUCATION
}

\begin{abstract}
This article aims to examine the social and sociological conditions which shape the changes in the definitions of urbanism and social memory, considering that these conditions, to some extent, engender perspectives for practices and research in patrimonial education. It is a diagnostic approach, based on conceptual reviews and analytical exercises based on contemporary social theory, from the Brazilian reality. It concludes that studies on the subject require the problematization of the static condition of the properties, practices or collectivities which their policies aim to protect, as well as demand the recognition of multiple and dialectical relations among collectivities, spatialities and heritage.
\end{abstract}

KEYWORDS: Patrimonial Education. Urbanism. Memory. Society.

\section{Perspectivas actuales para la investigación EN EDUCACIÓN PATRIMONIAL}

RESUMEN: En este artículo se pretende examinar las condiciones sociales y sociológicas que configuran transformaciones en las definiciones de urbanismo y de memoria social, considerando que tales condiciones, en alguna medida, 
engendran perspectivas para las prácticas y para la investigación en educación patrimonial. Se trata de un abordaje diagnóstico, basado en revisiones conceptuales y en ejercicios analíticos fundamentados en la teoría social contemporánea, a partir de la realidad brasileña. Se concluye que los estudios sobre el tema requieren el cuestionamiento de la condición estática de los bienes, las prácticas o colectivos a los que sus políticas están destinadas a proteger, así como exigir el reconocimiento de las múltiples y dialécticas relaciones entre las comunidades, la espacialidad y la patrimonialización.

PALABRAS CLAVE: Educación Patrimonial. Urbanismo. Memoria. Sociedad.

\section{Agradecimentos}

$\mathrm{O}$ autor agradece ao CNPq e à FAPERGS o financiamento dos projetos de pesquisa cujos dados são aqui parcialmente analisados.

\section{REFERÊNCIAS}

ABREU, R. Patrimonialização das diferenças e os novos sujeitos de direito coletivo no Brasil. In: TARDY, C.; DODEBEI, V. (Orgs.) Memória e novos patrimônios. Marseille: Open Edition Press, 2015.

BRENNER, N. O que é teoria crítica urbana? E-metrópolis, n.3, p.20-28, 2010.

BRENNER, N.; SCHMID, C. La "era urbana" en debate. EURE, v. 42, n. 127, p.307-339, 2016.

CANCLINI, N. G. Consumidores e cidadãos: conflitos multiculturais da globalização. 6. ed. Rio de Janeiro: Ed. UFRJ, 2006.

CANDAU, J. Memória e identidade. São Paulo: Contexto, 2016.

CASTELLS, M. A questão urbana. São Paulo: Paz e Terra, 2000.

CHOAY, F. O urbanismo. São Paulo: Perspectiva, 1983.

CORTÊS, C. Cultura, diversidade e política: transversalidade dos conceitos nas políticas culturais. In: RUBIM, A. A. C.; ROCHA, R. (Orgs.) Políticas culturais. Salvador: Ed. UFBA, 2012.

DÍAZ, D. El mapa de la memória. Puentes, n. 7, p. 34-39, 2002. 
DUBET, F. Sociologia da Experiência. Lisboa: Instituto Piaget, 1994.

FABRI, S. Lugares de memoria y marcación territorial: sobre la recuperación de los centros clandestinos de detención en Argentina y los lugares de memoria en España. Revista Colombiana de Geografía, v. 22, p.93-108, 2013.

. Los lugares de la memoria en Buenos Aires: Mansión Seré a diez años de su recuperación. GeoUSP, n. 29, p.169-183, 2011.

GONÇALVES, J. R. O patrimônio como categoria de pensamento. In: ABREU; R.; CHAGAS, M. (Orgs.) Memória e patrimônio: ensaios contemporâneos. Rio de Janeiro: DP\&A, 2003.

HARVEY, D. A condição pós-moderna. São Paulo: Loyola, 1989.

. A justiça social e a cidade. São Paulo: Hucitec, 1980.

NORA, P. Entre memória e história: a problemática dos lugares. Projeto História, n. 10, p.7-28, 1993.

POLLAK, M. Memória, esquecimento, silêncio. Estudos Históricos, v. 2, n. 3, p.3-15, 1989. RUBIM, A. A. Políticas culturais: entre o possível e o impossível. In: NUSSBAUMER, G. (Org.) Teorias e políticas da cultura: visões multidisciplinares. Salvador: Edufba, 2007.

SANTOS, M. Ensaios sobre a urbanização latino-americana. São Paulo: Hucitec, 1982. SCIFONI, S. Desafios para uma nova educação patrimonial. Teias, v. 18, n. 48, p.5-16, 2017. SILVA, R. M. D. Narrativas identitárias e educação patrimonial no Brasil. Teias, v.18, n. 48, p.17-36, 2017.

. Educação patrimonial e a dissolução das monoidentidades. Educar em Revista, n. 56, p.2017-224, 2015.

VALECILLO, Z. Como podemos evitar a morte social do patrimônio cultural? Educação patrimonial, uma área emergente. Mouseion, n. 23, p.41-56, 2016.

Recebido em 19/03/2018.

Aprovado em 05/12/2018. 